\title{
Landslides caught on seismic networks and satellite radars
}

\author{
Andrea Manconi ${ }^{1,2}$, Alessandro C. Mondini ${ }^{3}$, and the ALPARRAY Working Group ${ }^{+}$ \\ ${ }^{1}$ Department of Earth Sciences, Engineering Geology, ETH Zurich, Switzerland \\ $5 \quad{ }^{2}$ now at CERC, WSL Institute for Snow and Avalanche Research SLF, Switzerland \\ ${ }^{3}$ National Research Council, Istituto di Ricerca per la Protezione Idrogeologica, Perugia, Italy \\ ${ }^{+}$A full list of authors appears at the end of the paper \\ Correspondence to: Andrea Manconi (andrea.manconi@slf.ch)
}

10

\begin{abstract}
We present a procedure to detect landslide events by analysing in sequence data acquired from regional broadband seismic networks and spaceborne radar imagery. The combined used of these techniques is meant to exploit their complementary elements and mitigate their limitations when used singularly. To test the method, we consider a series of six slope failures associated to the Piz Cengalo rock avalanche recently occurred in the Swiss Alps, a region where we can

15 benefit from high spatial density and quality of seismic data, as well as from the high spatial and temporal resolution of the ESA Copernicus Sentinel-1 radar satellites. The operational implementation of the proposed approach, in combination with the future increase in availability of seismic and satellite data, can offer a new and efficient solution to build and/or expand landslide catalogues based on quantitative measurements, and thus help in hazard assessments and definition of early warning systems at regional scales.
\end{abstract}

\section{Introduction}

Landslides cause globally fatalities and devastation, with remarkable effects especially on low-income and/or developing countries (Froude and Petley, 2018). While the spatial occurrence of landslides is related to intrinsic geo-morphological, and climatic characteristics (Stead and Wolter, 2015), catastrophic failures arise when slope materials reach a critical damage state (Petley, 2004). In many cases, the ultimate trigger towards failure events is related to anthropic activities, extreme meteorological events, and earthquakes (Bayer et al., 2018; Huang et al., 2017; Lacroix et al., 2019).

Quantitative and accurate data on timing, location and size of landslides events are crucial to study the relationships between local and regional preconditioning factors, to recognize potential causes, as well as to identify the potential effects of climatic forcing. Moreover, efficient early warning systems at regional scale rely on the availability of accurate and complete landslide catalogues (Gariano and Guzzetti, 2016). Despite recent efforts, the knowledge on spatial and temporal landslide distribution is incomplete. The information about landslide volume, runout, velocity, etc. is usually available only when the events threat life or damage infrastructures, as well as when they are associated with large earthquakes or exceptional meteorological occurrences. These catalogues, however, deliver only a partial picture of the impact of such events on the landscape. In addition, many landslide events are unreported because they occur in remote regions and do not have immediate and/or relevant impacts on human activities. This strongly hinders the completeness of inventories used for hazard assessment and for calibration of early warning systems at regional scales (Guzzetti et al., 2019). 
In recent years, two methods have emerged in the panorama of landslide event detection, i.e. satellite remote sensing and seismic data analyses. This is mainly due to the increased availability and quality of these datasets at global scale, as well as to the open data access policies. In particular, Earth Observation (EO) data acquired through different satellite missions are more and more exploited by systematic visual interpretation, as well as supervised and unsupervised automatic classification methodologies, in order to build catalogues of landslide events triggered by large earthquakes and/or extreme meteorological events (Mondini et al., 2019; Tanyaş et al., 2017). These methodologies strongly depend on the availability of the images, which are usually not adequate for systematic early landslide detection. Further, despite the identification of signatures of landslide events in seismic networks deployed for earthquake monitoring is not a new observation (Govi et al., 2002; Weichert et al., 1994), technical advances and diffusion of broadband seismic sensors have increased the possibility to detect and locate also landslide events of small-moderate size at regional scales. Automatic or semi-automatic procedures adapted from earthquake location routines have demonstrated fair performances (Chao et al., 2017; Dammeier et al., 2011; Ekstrom, 2006; Fuchs et al., 2018); however, while uncertainties of several $\mathrm{km}$ can be tolerated in case of earthquake epicentral locations, landslides are extremely confined phenomena affecting a single slope (or only small portions of it). A more accurate location of the events can be achieved with local networks specifically designed to identify mass movements (Dietze et al., 2017; Cook and Dietze, 2022). Despite, such procedures are impractical at the scales of a mountain chain.

In this work, we jointly use broadband seismic data and spaceborne radar imagery to show a procedure allowing for a systematic detection and location of landslides, as well as an initial definition of their area of impact, and their magnitude. We present results over the region recently affected by the Piz Cengalo, a steep granitic massive located in the central Alps at the border between Switzerland and Italy (see Figure 1), The area was repeatedly affected by large (>1 Mm3), rock slope

55 failure processes in the past decades, with the main event on August 23, 2017, being the largest ( $>3$ Mm3) and most catastrophic reported in recent years, causing 8 fatalities as well as damages in the range of 50M\$. A detailed description of the event, its preconditioning factors, potential causes, the dynamics of the rock slope failure and the subsequent debris flow reaching the village of Bondo, is beyond the scope of this work. Thus, the readers are referred to the recent literature for more information on these specific topics (Mergili et al., 2019; Walter et al., 2019).

\section{Materials and Methods}

We consider Piz Cengalo as an exemplary case to demonstrate the potential and the limits of the combination of seismic and spaceborne radar data to provide quantitative information on landslide occurrence in an alpine scenario. We benefit from the high spatial density of the AlpArray seismic network (Hetényi et al., 2018) and from the unprecedented spatial and temporal resolution of Sentinel-1 Synthetic Aperture Radar (SAR) imagery (Torres et al., 2012). In the following, we describe the

65 steps to initially define a candidate location region with seismic data, and then apply change detection investigations on Sentinel-1 SAR imagery to refine the location and identify the slope failure event. Hereafter, we will use the term "landquake" to define "landslide events recorded by seismic sensors", as increasingly proposed in literature (Chen et al., 2013). However, this term is not meant to provide additional details on specific landslide characteristics. 

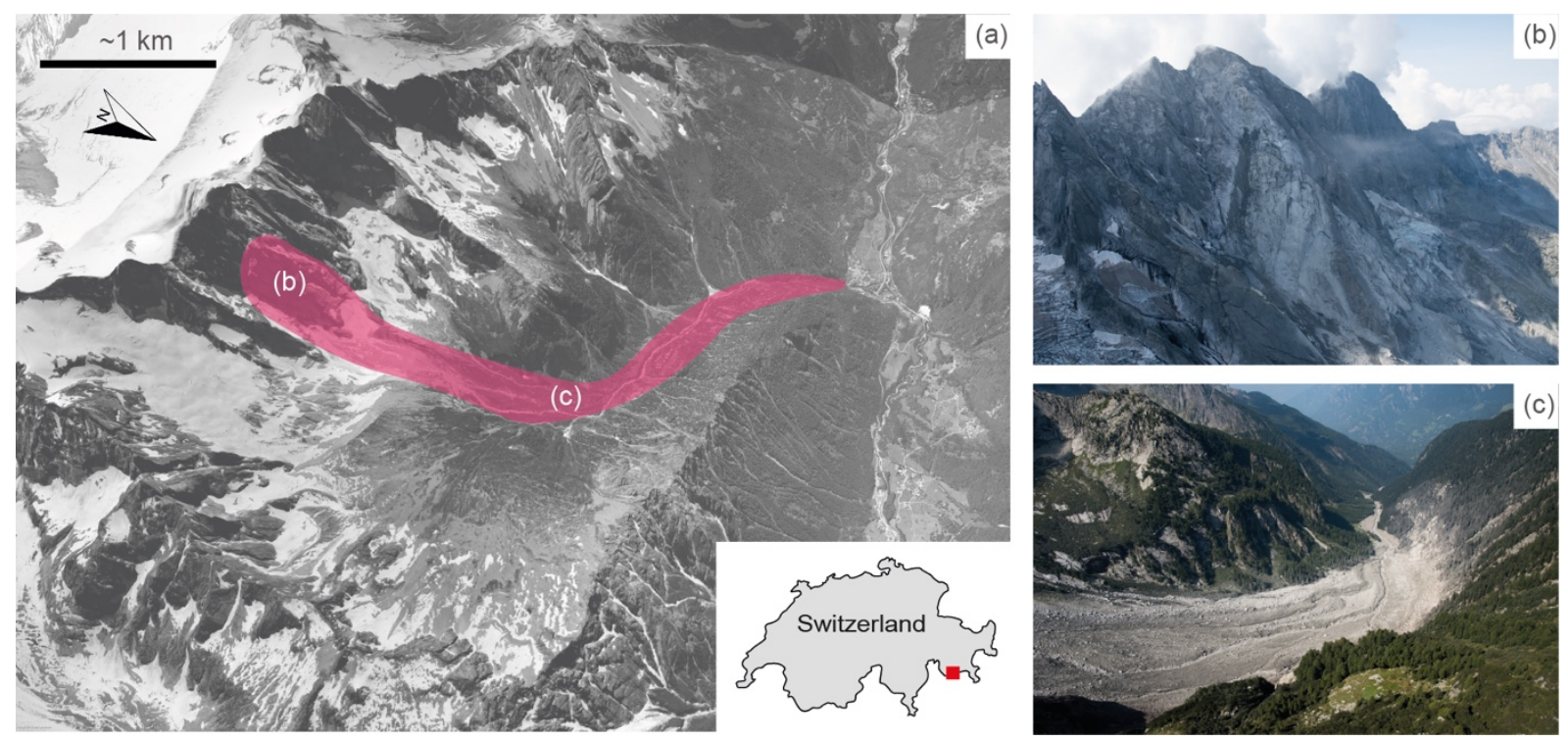

Figure 1: Overview of the area of investigation. (a) View of the Val Bondasca, with approximate outline of the area affected by the Piz Cengalo $\left(46.29475^{\circ} \mathrm{N}, 9.602056^{\circ} \mathrm{E}\right)$ rock avalanche and subsequent debris flows, $\subset$ Google Earth 2021; (b) Detail of the release area, August 25, 2017; (c) Detail of the deposits, August 30 2017. (C) Photos VBS swisstopo Flugdienst.

\subsection{Seismic data processing}

We consider a total of six events occurred at Piz Cengalo between August 21 and October 10, 2017 (see Table 1). The landquakes are characterized by different magnitude in terms of volumes and runout, and occurred all in the same slope but different stages of the progressive failure process: LQ1 occurred two days before the main failure, three events on August 23, 2017, (LQ2-LQ4), while LQ5 about a month later and LQ6 about two months later). Figure 2 shows the distribution of the AlpArray stations and examples of the signals for the LQ2 detected at different distances from the source. The apparent velocities are on the order of $3 \mathrm{~km} / \mathrm{s}$, thus compatible with surface waves generated by surficial mass movements (e.g., Dammeier et al., 2011). The Swiss Seismological Service (SED) routinely recognizes landslide phenomena in seismic records of stations located in Switzerland and in the vicinity of the national borders. Despite monitoring procedures are not optimized to detect mass movements, these are systematically reported. After an event detection (at least 3 stations triggered on the SED network), a first order manual solution is obtained by identifying coherent energy at multiple stations, identifying these typically as S-waves, by using a regional 3D velocity model. In general, locations are more accurate when seismic stations are close to the event and there is good azimuthal distribution of observations. For the Piz Cengalo landquake event associated to the largest failure (LQ2), the closest station is at $\sim 25 \mathrm{~km}$ and the location accuracy has uncertainties on the order of $\pm 5 \mathrm{~km}$. 
To perform our back analysis on the Piz Cengalo sequence, we define a temporal window of 10 minutes centred on the date and time provided by SED with the manual procedure described above. We consider the waveforms recorded by all the AlpArray broadband stations available for each event and focused on the HHZ channel (i.e., the vertical velocity component of high broad band sampled at or above $80 \mathrm{~Hz}$, generally 100 or $200 \mathrm{~Hz}$ ). The choice of the $\mathrm{HHZ}$ channel is justified by previous studies showing that such component usually entails the largest energy in case of landquakes (e.g., Dammeier et al., 2011). We apply a STA/LTA detection (see details and parameters in the Supporting Information, table S1) to find the onset time of the event at each station. Then, we compute the time delay between the first triggered station, assumed to be the closest to the event, and all the other stations identifying an event in the same temporal window. The resulting values are interpolated on a regular grid of $0.25 \times 0.25$ degrees, spatially smoothed with an average filter ( $3 \times 3$ kernel), and then normalized to obtain a new function defined here as "Likelihood of Landquake Location" (LLL). The candidate region of interest (ROI) potentially affected by a landquake is defined by considering LLL $>0.95$, and to target the change detection processing on a spatial subset of available Sentinel-1 radar scenes.

\begin{tabular}{|c|c|c|c|c|c|}
\hline $\begin{array}{c}\text { Event } \\
\text { ID }\end{array}$ & Date/Time (UTC) & ML & $\mathbf{M D}^{*}$ & $\mathbf{M L / M D}$ & Vol $\left(\mathbf{M m}^{3}\right)$ \\
\hline LQ1 & $2017-08-21 T 09: 29: 09$ & 2.3 & 3.03 & 0.75 & $0.078-0.167$ \\
\hline LQ2 & $2017-08-23 T 07: 30: 27$ & 3.0 & 3.71 & 0.80 & $1.65-2.61$ \\
\hline LQ3 & $2017-08-23 T 09: 03: 57$ & 1.3 & 2.86 & 0.45 & $0.02-0.14$ \\
\hline LQ4 & $2017-08-23 T 09: 36: 16$ & 2.1 & 3.22 & 0.65 & $0.12-0.50$ \\
\hline LQ5 & $2017-09-15 T 20: 04: 36$ & 2.3 & 3.26 & 0.70 & $0.23-0.41$ \\
\hline LQ6 & $2017-10-10 T 02: 58: 41$ & 1.1 & 2.65 & 0.41 & $0.014-0.035$ \\
\hline
\end{tabular}

Table 1. Summary of the landquakes analysed in this study and associated to the Piz Cengalo slope failure. ML are estimated by SED, while average magnitude duration (MD) and volumes are computed following Manconi et al., 2016, by considering the event duration on all triggered AlpArray stations. Note that all LQ events have ML/MD have ML/MD less or equal to 0.8, i.e. they can be discerned from earthquake events which typically have ML/MD $\sim 1$.

\subsection{Sentinel-1 SAR data processing}

We adopt the change detection processing proposed in (Mondini, 2017), here specifically modified to tackle single events instead of populations of landslides. The analysis is performed to identify potential variations of surface backscattering 
occurred between the pre- and post-event images, over the area with LLL $>0.95$ (projected into SAR coordinates). After data acquisition, pre-processing of the radar imagery includes radiometric, and geometric corrections, multi-looking, and filtering of the intensity values to obtain the radar brightness coefficient (Beta Nought, $\beta_{0}$ ) with a cell resolution of about $14 \mathrm{~m} \times 14$ $\mathrm{m}$. Changes of $\beta_{0}$ have demonstrated to be a suitable indicator for the detection of landslide events of different size and occurred in different geographic scenarios (Mondini et al., 2019). In the maps of $\beta_{0}$, changes, landslides appear as clusters of similar values in a bulk of speckles. The $\beta_{0}$ changes map is then segmented using a parametric watershed approach (Roerdink and Meijster, 2000) in which the scale level and the moving window kernel size parameters of the intensity algorithm are automatically assigned minimizing a cost function (Mondini, 2017). The segmentation process is aimed at identifying in the candidate area LLL $>0.95$ a unique segment (i.e., the largest, potentially delineating changes associated to the landquake) and a number of small segments intercepting the speckle-like effect present in the $\beta_{0}$ changes map. Thus, the landquake is recognized as an outlier in the segment's distribution of the areas. The boundaries of the outlier segment, reprojected from SAR to ground coordinates, provide the potential location of the landquake.
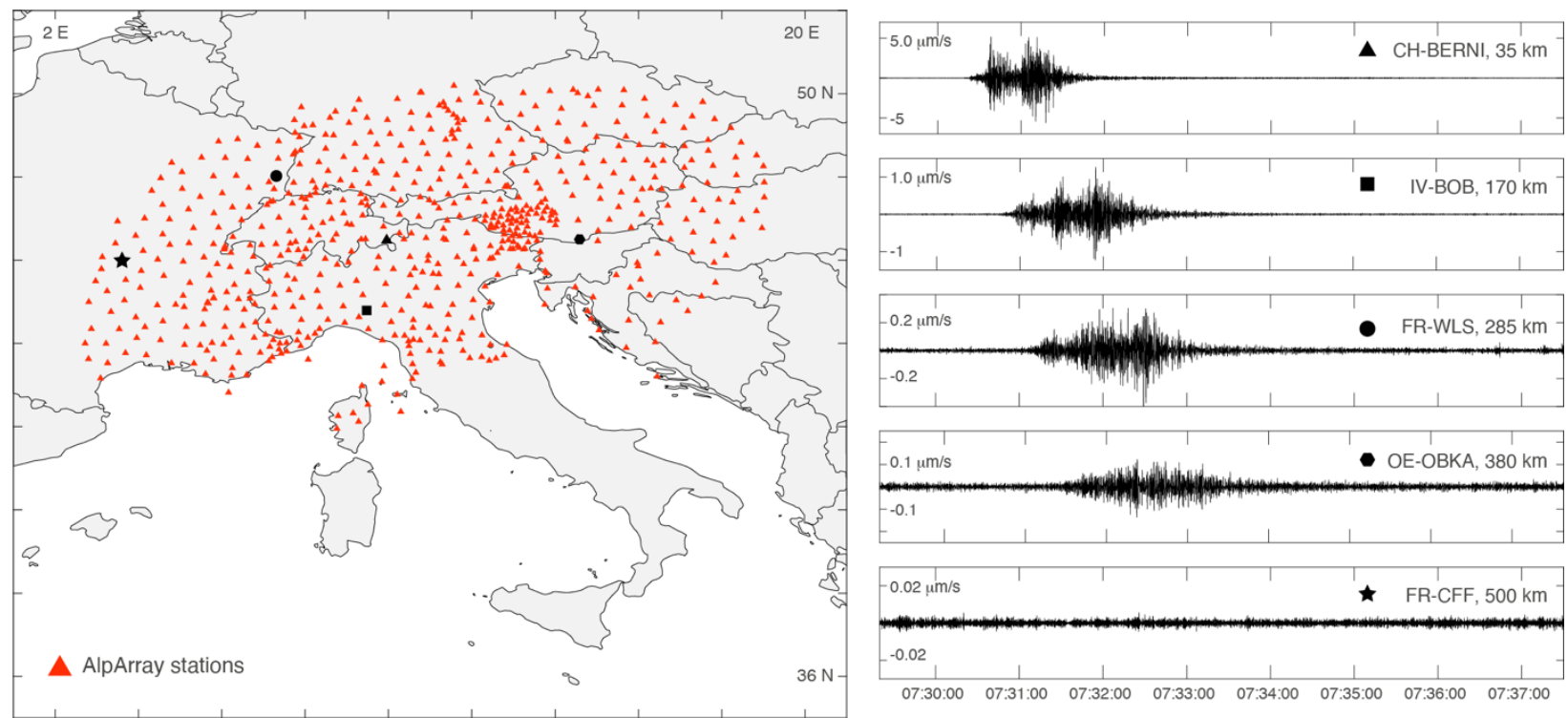

Figure 2. Seismic network and data (left) The AlpArray network of broad band stations. (right) Selected signals (vertical component HHZ) recorded by AlpArray stations located at different distances from event LQ2 (see table 1), occurred on August 23, 2017 (i.e., the main Piz Cengalo rock avalanche event).

\section{Results}

Figure 3 shows the exemplary results obtained by analysing the seismic data available for the LQ2 event. This is the largest landquake, and its seismic signature was detected by tens of stations up to $\sim 400 \mathrm{~km}$ distance from the source (see also 
135 Supporting Information). The computed LLL function is approximately centred on Piz Cengalo massive. The area within LLL $>0.95$ is in the order of $10,000 \mathrm{~km} 2$, i.e. $\sim 1 \%$ of the entire seismic network considered (the AlpArray covers $\sim 1$ Million $\mathrm{km}^{2}$ ). However, this is still very large for an accurate identification of a slope failure event affecting an area of about $1 \mathrm{~km} 2$ (Walter et al., 2019).

The initial candidate region defined by the LLL function is used to first identify the available Sentinel-1 imagery in terms of 140 time of acquisition and orbit. In this specific case, the suitable Sentinel-1 orbits are the T015, ascending, and T066, descending, respectively. Then, the change detection processing is not applied to the entire image, but only to the area with LLL $>0.95$, which is $20 \%$ of the acquired SAR scene. Figure 4 shows the best results of the change detection analysis obtained on the ascending T015 imagery (see Supporting Information, Table S2). Due to the temporal proximity of the LQ1LQ4 sequence (occurred within two days, see Table 1), the LQ2 event cannot be singularly discriminated, because the

145 Sentinel-1 constellation (when both Sentinel-1A and 1B are operative) revisit time in Europe is of six days. The LQ2, however, has been certainly the main cause of the surface changes, and for this reason we refer hereafter mainly to this event. The outlier segment that identified covers an area of $\sim 0.9 \mathrm{~km} 2$, about two orders of magnitude larger than the average areas of the segment's distribution. The footprint and the dimensions of this segment are in very good agreement with the area affected by the rock avalanche (Walter et al., 2019). The events LQ5 and LQ6 are smaller in magnitude, and the changes on the SAR image cannot be univocally defined as for the LQ2 (see Supporting Information, Figure S2 and S3). Nevertheless, the location of the largest segments identified within the Bondasca valley fall very near to the area affected by the Piz Cengalo landquake sequence.

\section{Discussion}

Seismic data are capable to provide an indirect evidence of the time of landslide occurrence also in inaccessible locations, but independent verification of the location is necessary for event confirmation and classification (Ekström and Stark, 2013). On the other hand, remote sensing data can deliver direct evidence of the areas hit by landslide events, but independent observations are necessary to identify the exact time of occurrence (Guzzetti et al., 2012). We propose an approach exploiting seismic and remote sensing (specifically, space borne SAR data), which is suitable for the development of automatic pipelines aimed at a systematic identification, location and first evaluation of landslides. We have shown as an exemplary case the application to a sequence of events recently occurred in the Swiss Alps. Our results provide several hints on the potential application of this approach in operational scenarios. We have applied a STA/LTA approach for the identification of the event on an arbitrary constrained temporal window. The STA/LTA method has shown to be suitable for the automatic detection of mass movements in continuous seismic records also for early warning purposes, although specific calibration of the parameters used is necessary and depend on the sensors, the network configuration, and local conditions

165 (Coviello et al., 2019). 


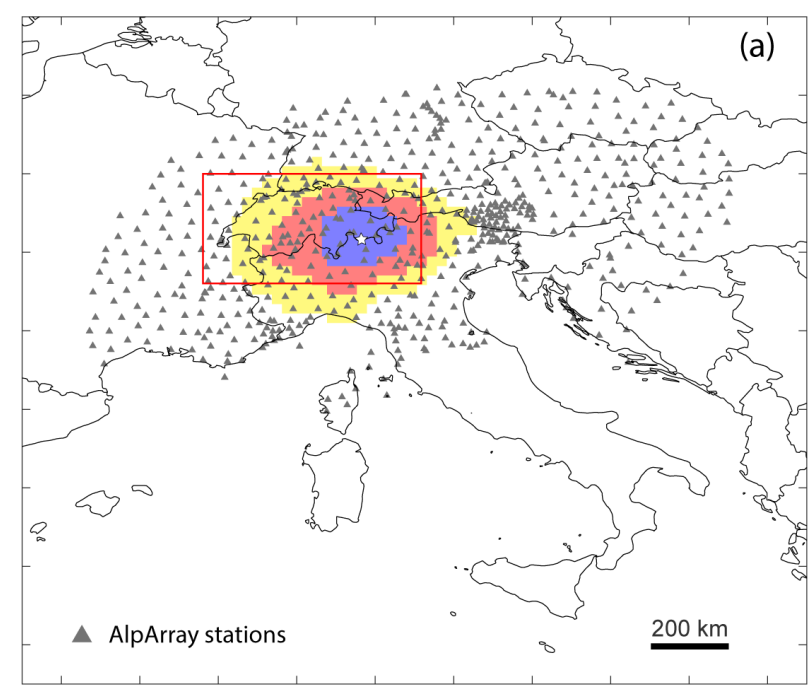
is Piz Cengalo
$\Delta$ Triggered
$0.85<\mathrm{LLL}<0.90$
$\triangle$ Not Triggered
$0.90<\mathrm{LLL}<0.95$
- No Data
$0.95<\mathrm{LLL}<1.00$

Landquake Location Likelihood

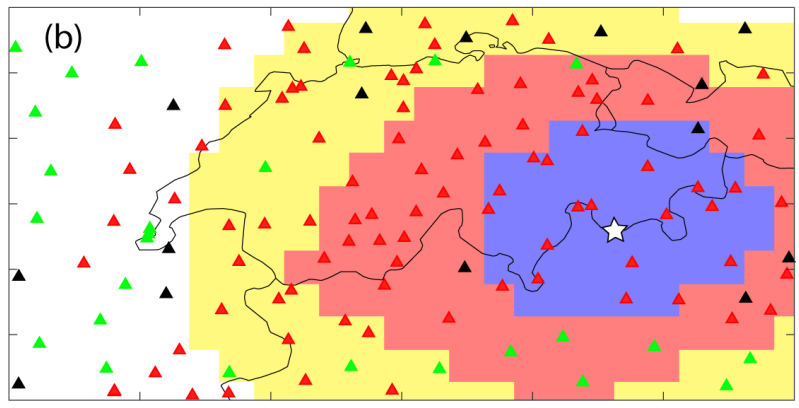

Figure 3. Likelihood of Landquake Location (LLL) based on the arrival time of seismic signals recorded by AlpArray stations. over the entire AlpArray network (b) Zoom on the areas with high likelihood. The area $0.95<L L L<1.0$ is used to confine the change detection analysis. True location of the Piz Cengalo event (white star) is also shown.

One of the main arguments against the use of the STA/LTA approach in the detection of mass movement signals lies in the inaccuracy for the determination of the event's onset, which might cause errors on the subsequent location procedures (Fuchs et al., 2018). Since we refine the location using the remote sensing imagery, the STA/LTA approach is sufficient to constrain the candidate region for the change detection task. Inaccuracies up to seconds of the STA/LTA detection that would cause large inaccuracies in location routines based on seismic data only, would cause only negligible changes on the LLL function. Despite the candidate location is identified with a basic proximity approach, the source region is already reasonably well 
180 constrained for all six LQ events considered (see also Supporting Information, Figure S1). This result is possible only when a relatively high spatial density of seismic sensors is available, such as the AlpArray network. More advanced location routines can be applied, but homogenization of procedures across large areas like entire alpine chain is not straightforward. In addition, an increased level of complexity would not correspond to an increase of accuracies for landslide location.

Another important problem after detection is the distinction and/or classification of the signals recorded in continuous seismic waveforms (e.g., earthquakes, explosion, mass movements, anthropic sources, etc.). Several authors proposed empirical based relationships, signal processing and/or or machine learning strategies, achieving good performances (Dammeier et al., 2016; Hibert et al., 2014; Moore et al., 2017). Here we considered the method proposed in (Manconi et al., 2016), based on the ratio between the local magnitude and the duration magnitude, to distinguish between local earthquakes and landquakes. The results show that with this approach the Piz Cengalo sequence could have been automatically classified 190 as landquakes (see Table 1). This strategy, including the empirical evaluation of the rockslide volumes based on the empirical relationship observed with the duration magnitude, has been recently implemented in an operational regional system in Taiwan showing encouraging results (Chang et al., 2020).

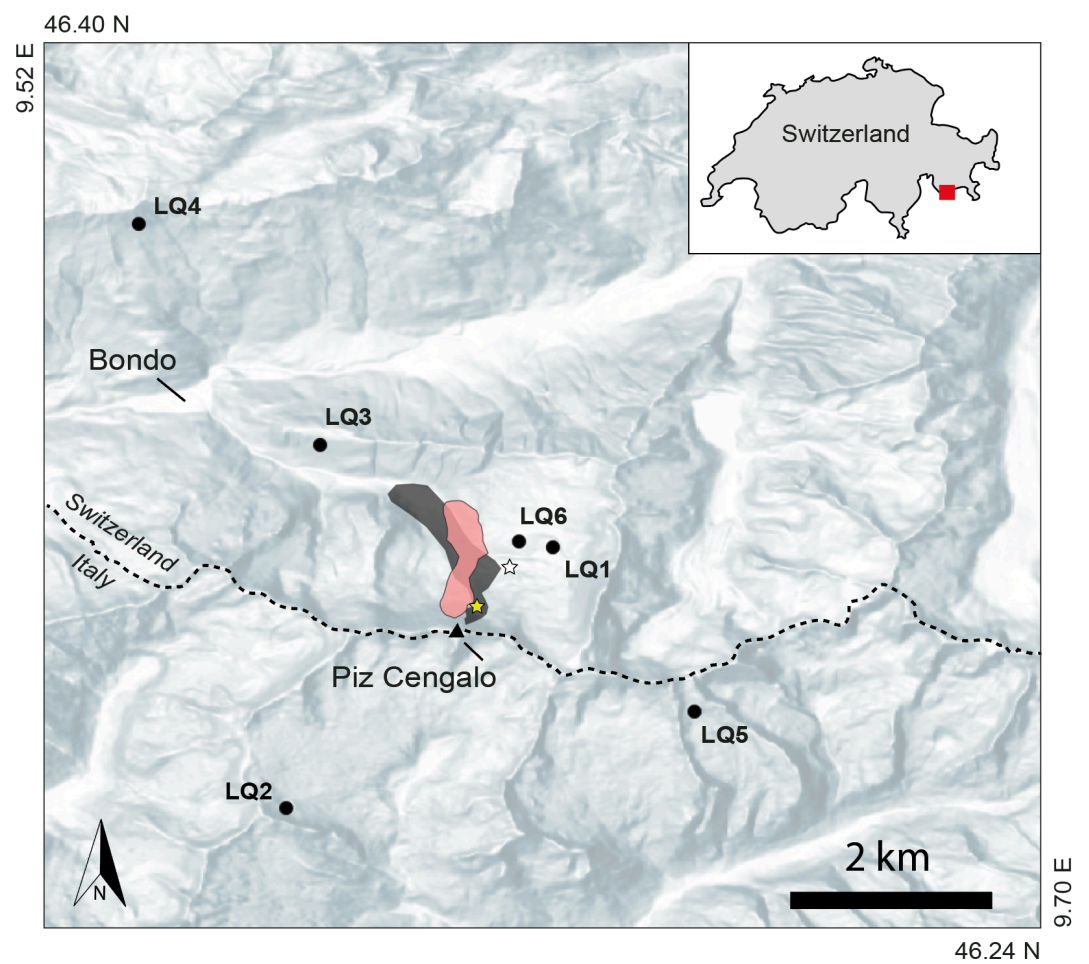

Figure 4. Results of the change detection analysis. The red polygon shows the area identified as potential landquake location for the main Landquake event (i.e., LQ1-LQ4) identified by processing the Sentinel-1 pre- and post-event, while the grey polygon is the area hit by the rock avalanche (cf. Walter et al., 2019). The white star and the yellow star show the locations of the largest segments for LQ5 and LQ6, respectively, identified within the Bondasca valley. The black dots show the epicentral locations provided by SED (see Table 1). 
As far as the change detection analysis on the Sentinel-1 SAR data is concerned, the location of landquakes as the LQ2 (i.e. in this case the LQ1-LQ4 sequence) is straightforward. The event was large and caused a relevant drop of the backscattering coefficient in the post event image, spatially over sizing the surrounding random changes always present in SAR images (speckling-like effect). Furthermore, other environmental changes in the area are not relevant, and in this specific case, mostly in the direction of an increase of the backscattering coefficient. The results of the segmentation are unambiguous in all the images whatever the acquisition mode and the polarization are, even if the final segments can be slightly different. Additionally, post processing, like smoothing or gap-filling filtering, can also change partially the final shape of the segment and the identified area. On the contrary, the identification of the LQ5 and LQ6 events shows more complexity and it is not straightforward. According to seismic data, their sizes are smaller compared to LQ2, and then corresponding changes of the backscattering coefficient are expected to be less prominent in the bulk of random speckles. When the signs left on the SAR image amplitude have a size comparable the speckling-like segments, landslides cannot be univocally recognized. Regarding LQ5, the entire area of investigation was also affected by distributed environmental changes dropping the backscattering coefficient, which can be affected by snow and/or other atmospheric disturbances. Only a supervised post processing (i.e., further filtering) over the valley, which facilitated the segmentation, allowed to highlight a potential cluster of interest. For LQ6, a small but clear signal is present in the catchment, along the slope, but is not the largest in size considering the entire

215 distribution of segments. There are other signals present in the neighbouring valleys that could mislead the analysis. For LQ5 and LQ6, the signals emerge only in the ascending imagery with VH polarization, another possible indication of the change of roughness along the slope (Sung and Holzer, 1976). A potential adaption for the operational implementation of our approach could be running the change detection task on progressively increasing LLL thresholds (e.g., 0.95, 0.975, etc.). This could provide additional hints on possible hot-spots, which can be verified with subsequent SAR acquisitions and/or supplementary remote sensing imagery (space-borne or air-borne).

\section{Conclusions}

The key take-home message of this study is to show how the systematic combination of seismic and remote sensing data can be useful for identification and mapping of landslide events. The use of SAR satellites shows the advantages of all weather, day and night, and systematic acquisitions at global scale. When available, optical imagery and/or SAR imagery acquired with different bands, full polarimetric, or with higher spatial resolution can eventually contribute to an increase the quality and the quantity of the information. We believe that combining seismic and spaceborne data is a viable approach for a future operational monitoring system at the scale of the Alps, and for this reason this work can be the starting point to raise awareness in the community, as well as to foster cooperation and the funding necessary for such an endeavour. We conclude remarking that our approach is not intended to be used for early recognition of landslides or as early warning tool. The main goal of an operational implementation could be to systematically populate landslide catalogues relying on quantitative and accurate information on timing, magnitude, and frequency also in remote areas. Improved catalogue completeness is very important for the calibration of regional early warning systems based on rainfall thresholds, as well as on regional hazard 
assessments (Guzzetti et al., 2019). The availability of remote sensing imagery with daily or sub-daily revisit times could lead to an employment in early detection of landslide events and possibly also in disaster response scenarios, but these potential applications have to be evaluated in future studies.

\section{Team List}

Components of the AlpArray Working group (23 January 2021, see details at: http://www.alparray.ethz.ch/):

György HETÉNYI, Rafael ABREU, Ivo ALLEGRETTI, Maria-Theresia APOLONER, Coralie AUBERT, Simon

BESANÇON, Maxime BÈS DE BERC, Götz BOKELMANN, Didier BRUNEL, Marco CAPELLO, Martina ČARMAN, Adriano CAVAliERE, Jérôme CHÈZE, Claudio CHIARABBA, John CLINTON, Glenn COUGOULAT, Wayne C. CRAWFORD, Luigia CRISTIANO, Tibor CZIFRA, Ezio D'ALEMA, Stefania DANESI, Romuald DANIEL, Anke DANNOWSKI, Iva DASOVIĆ, Anne DESCHAMPS, Jean-Xavier DESSA, Cécile DOUBRE, Sven EGDORF, ETHZ-SED Electronics Lab, Tomislav FIKET, Kasper FISCHER, Wolfgang FRIEDERICH, Florian FUCHS, Sigward FUNKE, 245 Domenico GIARDINI, Aladino GOVONI, Zoltán GRÁCZER, Gidera GRÖSCHL, Stefan HEIMERS, Ben HEIT, Davorka HERAK, Marijan HERAK, Johann HUBER, Dejan JARIĆ, Petr JEDLIČKA, Yan JIA, Hélène JUND, Edi KISSLING, Stefan KLINGEN, Bernhard KLOTZ, Petr KOLÍNSKÝ, Heidrun KOPP, Michael KORN, Josef KOTEK, Lothar KÜHNE, Krešo KUK, Dietrich LANGE, Jürgen LOOS, Sara LOVATI, Deny MALENGROS, Lucia MARGHERITI, Christophe MARON, Xavier MARTIN, Marco MASSA, Francesco MAZZARINI, Thomas MEIER, Laurent MÉTRAL, Irene MOLINARI, Milena MORETTI, Anna NARDI, Jurij PAHOR, Anne PAUL, Catherine PÉQUEGNAT, Daniel PETERSEN, Damiano PESARESI, Davide PICCININI, Claudia PIROMALLO, Thomas PLENEFISCH, Jaroslava PLOMEROVÁ, Silvia PONDRELLI, Snježan PREVOLNIK, Roman RACINE, Marc RÉGNIER, Miriam REISS, Joachim RITTER, Georg RÜMPKER, Simone SALIMBENI, Marco SANTULIN, Werner SCHERER, Sven SCHIPPKUS, Detlef SCHULTEKORTNACK, Vesna ŠIPKA, Stefano SOLARINO, Daniele SPALLAROSSA, Kathrin SPIEKER, Josip STIPČEVIĆ, 255 Angelo STROLlO, Bálint SÜLE, Gyöngyvér SZANYI, Eszter SZÜCS, Christine THOMAS, Martin THORWART, Frederik TILMANN, Stefan UEDING, Massimiliano VALLOCCHIA, Luděk VECSEY, René VOIGT, Joachim WASSERMANN, Zoltán WÉBER, Christian WEIDLE, Viktor WESZTERGOM, Gauthier WEYLAND, Stefan WIEMER, Felix WOLF, David WOLYNIEC, Thomas ZIEKE, Mladen ŽIVČIĆ, Helena ŽLEBČÍKOVÁ.

\section{Author Contribution}

260 AM and ACM: Conceptualization, data analysis, manuscript writing and revision. ALPARRAY working group: Seismic data collection and maintenance.

\section{Competing interests}

The authors declare that they have no conflict of interest. 


\section{References}

265 Bayer, B., Simoni, A., Mulas, M., Corsini, A., and Schmidt, D.: Deformation responses of slow moving landslides to seasonal rainfall in the Northern Apennines, measured by InSAR, Geomorphology, 308, 293-306, https://doi.org/10.1016/j.geomorph.2018.02.020, 2018.

Chang, J.-M., Chao, W.-A., Chen, H., Kuo, Y.-T., and Yang, C.-M.: Locating rock slope failures along highways and understanding their physical processes using seismic signals, Earth Surf. Dyn. Discuss., 1-20, https://doi.org/10.5194/esurf2020-94, 2020.

Chao, W.-A., Wu, Y.-M., Zhao, L., Chen, H., Chen, Y.-G., Chang, J.-M., and Lin, C.-M.: A first near real-time seismologybased landquake monitoring system, Sci. Rep., 7, https://doi.org/10.1038/srep43510, 2017.

Chen, C.-H., Chao, W.-A., Wu, Y.-M., Zhao, L., Chen, Y.-G., Ho, W.-Y., Lin, T.-L., Kuo, K.-H., and Chang, J.-M.: A seismological study of landquakes using a real-time broad-band seismic network, Geophys. J. Int., 194, 885-898, 275 https://doi.org/10.1093/gji/ggt121, 2013.

Cook, K. L. and Dietze, M.: Seismic Advances in Process Geomorphology, Annu. Rev. Earth Planet. Sci., 50, null, https://doi.org/10.1146/annurev-earth-032320-085133, 2022.

Coviello, V., Arattano, M., Comiti, F., Macconi, P., and Marchi, L.: Seismic Characterization of Debris Flows: Insights into Energy Radiation and Implications for Warning, J. Geophys. Res. Earth Surf., 124, 1440-1463, https://doi.org/10.1029/2018JF004683, 2019.

Dammeier, F., Moore, J. R., Haslinger, F., and Loew, S.: Characterization of alpine rockslides using statistical analysis of seismic signals, J. Geophys. Res. Earth Surf., 116, F04024, https://doi.org/10.1029/2011JF002037, 2011.

Dammeier, F., Moore, J. R., Hammer, C., Haslinger, F., and Loew, S.: Automatic detection of alpine rockslides in continuous seismic data using Hidden Markov Models, J. Geophys. Res. Earth Surf., 2015JF003647, 285 https://doi.org/10.1002/2015JF003647, 2016.

Dietze, M., Turowski, J. M., Cook, K. L., and Hovius, N.: Spatiotemporal patterns, triggers and anatomies of seismically detected rockfalls, Earth Surf. Dyn., 5, 757-779, https://doi.org/10.5194/esurf-5-757-2017, 2017.

Ekstrom, G.: Global Detection and Location of Seismic Sources by Using Surface Waves, Bull. Seismol. Soc. Am., 96, 1201-1212, https://doi.org/10.1785/0120050175, 2006.

Ekström, G. and Stark, C. P.: Simple scaling of catastrophic landslide dynamics, Science, 339, 1416-1419, 2013.

Froude, M. J. and Petley, D. N.: Global fatal landslide occurrence from 2004 to 2016, Nat. Hazards Earth Syst. Sci., 18, 2161-2181, https://doi.org/10.5194/nhess-18-2161-2018, 2018.

Fuchs, F., Lenhardt, W., Bokelmann, G., and the AlpArray Working Group: Seismic detection of rockslides at regional scale: examples from the Eastern Alps and feasibility of kurtosis-based event location, Earth Surf. Dyn., 6, 955-970, https://doi.org/10.5194/esurf-6-955-2018, 2018.

Gariano, S. L. and Guzzetti, F.: Landslides in a changing climate, Earth-Sci. Rev., 162, 227-252, https://doi.org/10.1016/j.earscirev.2016.08.011, 2016.

Govi, M., Gullà, G., and Nicoletti, P. G.: Val Pola rock avalanche of July 28, 1987, in Valtellina (Central Italian Alps), in: Reviews in Engineering Geology, vol. 15, Geological Society of America, 71-90, https://doi.org/10.1130/REG15-p71, 2002. 
https://doi.org/10.5194/nhess-2022-34

Preprint. Discussion started: 15 February 2022

(c) Author(s) 2022. CC BY 4.0 License.

Guzzetti, F., Mondini, A. C., Cardinali, M., Fiorucci, F., Santangelo, M., and Chang, K.-T.: Landslide inventory maps: New tools for an old problem, Earth-Sci. Rev., 112, 42-66, https://doi.org/10.1016/j.earscirev.2012.02.001, 2012.

Guzzetti, F., Gariano, S. L., Peruccacci, S., Brunetti, M. T., Marchesini, I., Rossi, M., and Melillo, M.: Geographical landslide early warning systems, Earth-Sci. Rev., 102973, https://doi.org/10.1016/j.earscirev.2019.102973, 2019.

Hetényi, G., Molinari, I., Clinton, J., Bokelmann, G., Bondár, I., Crawford, W. C., Dessa, J.-X., Doubre, C., Friederich, W., 305 Fuchs, F., Giardini, D., Gráczer, Z., Handy, M. R., Herak, M., Jia, Y., Kissling, E., Kopp, H., Korn, M., Margheriti, L., Meier, T., Mucciarelli, M., Paul, A., Pesaresi, D., Piromallo, C., Plenefisch, T., Plomerová, J., Ritter, J., Rümpker, G., Šipka, V., Spallarossa, D., Thomas, C., Tilmann, F., Wassermann, J., Weber, M., Wéber, Z., Wesztergom, V., Živčić, M., Abreu, R., Allegretti, I., Apoloner, M.-T., Aubert, C., Besançon, S., Bès de Berc, M., Brunel, D., Capello, M., Čarman, M., Cavaliere, A., Chèze, J., Chiarabba, C., Cougoulat, G., Cristiano, L., Czifra, T., D’Alema, E., Danesi, S., Daniel, R.,

310 Dannowski, A., Dasović, I., Deschamps, A., Egdorf, S., Fiket, T., Fischer, K., Funke, S., Govoni, A., Gröschl, G., Heimers, S., Heit, B., Herak, D., Huber, J., Jarić, D., Jedlička, P., Jund, H., Klingen, S., Klotz, B., Kolínský, P., Kotek, J., Kühne, L., Kuk, K., Lange, D., Loos, J., Lovati, S., Malengros, D., Maron, C., Martin, X., Massa, M., Mazzarini, F., Métral, L., Moretti, M., Munzarová, H., Nardi, A., Pahor, J., Péquegnat, C., Petersen, F., Piccinini, D., Pondrelli, S., Prevolnik, S., Racine, R., Régnier, M., Reiss, M., Salimbeni, S., et al.: The AlpArray Seismic Network: A Large-Scale European Experiment to Image the Alpine Orogen, Surv. Geophys., 39, 1009-1033, https://doi.org/10.1007/s10712-018-9472-4, 2018.

Hibert, C., Mangeney, A., Grandjean, G., Baillard, C., Rivet, D., Shapiro, N. M., Satriano, C., Maggi, A., Boissier, P., Ferrazzini, V., and Crawford, W.: Automated identification, location, and volume estimation of rockfalls at Piton de la Fournaise volcano, J. Geophys. Res. Earth Surf., 119, 1082-1105, https://doi.org/10.1002/2013JF002970, 2014.

Huang, J., Fenton, G., Griffiths, D. V., Li, D., and Zhou, C.: On the efficient estimation of small failure probability in slopes, Landslides, 14, 491-498, https://doi.org/10.1007/s10346-016-0726-2, 2017.

Lacroix, P., Dehecq, A., and Taipe, E.: Irrigation-triggered landslides in a Peruvian desert caused by modern intensive farming, Nat. Geosci., 1-5, https://doi.org/10.1038/s41561-019-0500-x, 2019.

Manconi, A., Picozzi, M., Coviello, V., De Santis, F., and Elia, L.: Real-time detection, location, and characterization of rockslides using broadband regional seismic networks, Geophys. Res. Lett., 43, 2016GL069572, https://doi.org/10.1002/2016GL069572, 2016.

Mergili, M., Jaboyedoff, M., Pullarello, J., and Pudasaini, S. P.: Back-calculation of the 2017 Piz Cengalo-Bondo landslide cascade with r.avaflow, Nat. Hazards Earth Syst. Sci. Discuss., 1-30, https://doi.org/10.5194/nhess-2019-204, 2019.

Mondini, A. C.: Measures of Spatial Autocorrelation Changes in Multitemporal SAR Images for Event Landslides Detection, Remote Sens., 9, 554, https://doi.org/10.3390/rs9060554, 2017.

330 Mondini, A. C., Santangelo, M., Rocchetti, M., Rossetto, E., Manconi, A., and Monserrat, O.: Sentinel-1 SAR Amplitude Imagery for Rapid Landslide Detection, Remote Sens., 11, 760, https://doi.org/10.3390/rs11070760, 2019.

Moore, J. R., Pankow, K. L., Ford, S. R., Koper, K. D., Hale, J. M., Aaron, J., and Larsen, C. F.: Dynamics of the Bingham Canyon rock avalanches (Utah, USA) resolved from topographic, seismic, and infrasound data, J. Geophys. Res. Earth Surf., 2016JF004036, https://doi.org/10.1002/2016JF004036, 2017.

335 Petley, D. N.: The evolution of slope failures: mechanisms of rupture propagation, Nat Hazards Earth Syst Sci, 4, 147-152, https://doi.org/10.5194/nhess-4-147-2004, 2004.

Roerdink, J. B. T. M. and Meijster, A.: The Watershed Transform: Definitions, Algorithms and Parallelization Strategies, Fundam. Informaticae, 41, 187-228, https://doi.org/10.3233/FI-2000-411207, 2000. 
Stead, D. and Wolter, A.: A critical review of rock slope failure mechanisms: The importance of structural geology, J. Struct. 340 Geol., 74, 1-23, https://doi.org/10.1016/j.jsg.2015.02.002, 2015.

Sung, C. C. and Holzer, J. A.: Scattering of electromagnetic waves from a rough surface, Appl. Phys. Lett., 28, 429-431, https://doi.org/10.1063/1.88809, 1976.

Tanyaş, H., van Westen, C. J., Allstadt, K. E., Anna Nowicki Jessee, M., Görüm, T., Jibson, R. W., Godt, J. W., Sato, H. P., Schmitt, R. G., Marc, O., and Hovius, N.: Presentation and Analysis of a Worldwide Database of Earthquake-Induced 345 Landslide Inventories, J. Geophys. Res. Earth Surf., 122, 2017JF004236, https://doi.org/10.1002/2017JF004236, 2017.

Torres, R., Snoeij, P., Geudtner, D., Bibby, D., Davidson, M., Attema, E., Potin, P., Rommen, B., Floury, N., Brown, M., Traver, I. N., Deghaye, P., Duesmann, B., Rosich, B., Miranda, N., Bruno, C., L’Abbate, M., Croci, R., Pietropaolo, A., Huchler, M., and Rostan, F.: GMES Sentinel-1 mission, Remote Sens. Environ., 120, 9-24, https://doi.org/10.1016/j.rse.2011.05.028, 2012.

350 Walter, F., Amann, F., Kos, A., Kenner, R., Phillips, M., de Preux, A., Huss, M., Tognacca, C., Clinton, J., Diehl, T., and Bonanomi, Y.: Direct observations of a three million cubic meter rock-slope collapse with almost immediate initiation of ensuing debris flows, Geomorphology, 106933, https://doi.org/10.1016/j.geomorph.2019.106933, 2019.

Weichert, D., Horner, R. B., and Evans, S. G.: Seismic signatures of landslides: The 1990 Brenda Mine collapse and the 1965 hope rockslides, Bull. Seismol. Soc. Am., 84, 1523-1532, 1994. 